\title{
Adherence to Drug Medications amongst Tuberculosis Patients in a Tertiary Health Institution in South East Nigeria
}

\author{
Chika F. Ubajaka1*, Emmanuel C. Azuike1, John O. Ugoji², Onyema E. Nwibo3, \\ Obiorah C. Ejiofor', Ifeoma A. Modebe1, Uche M. Umeh'1 \\ ${ }^{1}$ Department of Community Medicine, Nnamdi Azikiwe University Teaching Hospital, Nnewi, Nigeria \\ ${ }^{2}$ Department of Pharmacy, Nnamdi Azikiwe University Teaching Hospital, Nnewi, Nigeria \\ ${ }^{3}$ Department of Surgery, Nnamdi Azikiwe University Teaching Hospital, Nnewi, Nigeria \\ ${ }^{4}$ Department of Paediatrics, Anambra State University Teaching Hospital, Amaku, Nigeria \\ Email: ${ }^{*}$ chika@grunzlink.com
}

Received 24 April 2015; accepted 9 June 2015; published 12 June 2015

Copyright () 2015 by authors and Scientific Research Publishing Inc.

This work is licensed under the Creative Commons Attribution International License (CC BY).

http://creativecommons.org/licenses/by/4.0/

(c) (i) Open Access

\section{Abstract}

Tuberculosis remains one of the major health problems in many tropical countries. An estimated eight to ten million people develop overt tuberculosis annually worldwide as a result of primary infection, endogenous reactivation or exogenous re-infection. About half of all patients with TB do not complete treatment and this contributes to prolonged infectiousness, drug resistance, relapse and death. This study is aimed at assessing the adherence of TB patients to anti-TB medications as well as the factors influencing drug adherence in a tertiary health care institution in South-Eastern Nigeria. A descriptive cross-sectional study was conducted among 217 TB patients in Nnamdi Azikiwe University Teaching Hospital, Nnewi. Information was obtained using a self-administered and interviewer administered semi-structured questionnaire. The mean age of the respondents is $36.1 \pm 13.3$ years. More of the respondents were females $(58.1 \%)$, while $41.9 \%$ were males. It was observed that $74.2 \%$ had never failed to take their anti-TB drugs while $24.2 \%$ agreed they had failed to take their drugs. The major reasons for failure to take drugs were no money for transport to collect new drugs and forgetfulness by $32.7 \%$ of the respondents respectively. The factors which influenced drug adherence were educational qualification, average monthly income, illhealth as a financial burden and receiving HIV drugs $(P<0.05)$. Adherence towards anti-TB medications is good. However, efforts need to be intensified to educate and encourage TB patients to adhere strictly to their drugs as this will be of great value to them and the community at large.

\footnotetext{
${ }^{*}$ Corresponding author.
}

How to cite this paper: Ubajaka, C.F., Azuike, E.C., Ugoji, J.O., Nwibo, O.E., Ejiofor, O.C., Modebe, I.A. and Umeh, U.M. (2015) Adherence to Drug Medications amongst Tuberculosis Patients in a Tertiary Health Institution in South East Nigeria. International Journal of Clinical Medicine, 6, 399-406. http://dx.doi.org/10.4236/ijcm.2015.66052 
Keywords

Adherence, Drug Medications, Tuberculosis

\section{Introduction}

Tuberculosis remains one of the major health problems in many tropical countries. An estimated eight to ten million people develop overt tuberculosis annually worldwide as a result of primary infection, endogenous reactivation or exogenous re-infection [1]. Tuberculosis is caused by bacteria of the genus mycobacterium which are slender, aerobic rods that grow in straight or branching chains. It is acquired by inhalation of infected droplets coughed out by infected persons and by consumption of unpasteurized milk from infected cow. Tuberculosis flourishes wherever there is poverty, overcrowding and chronic debilitating illness [2]. TB can affect any organ in the body but most commonly affects the respiratory system from where it can disseminate to involve other parts of the body [3]. Diagnosis of TB is made by sputum microscopy using Ziehl-Neelsen method. Other diagnostic methods are chest X-ray and sputum culture using Lowenstein Jensen medium or Guinea pig inoculation [4].

Tuberculosis was declared as a global emergency by World Health Organization (WHO) in April 1993 due to its enormous threat to the world. In March 2000, a conference of Health Ministers from the twenty countries with the highest TB burden was held in Amsterdam where the "STOP TB" initiative was signed [1]. This initiative embarked on the Directly Observed Treatment Short Course (DOTS) as the internationally recommended TB control strategy. It has been shown that if DOTS is accurately implemented, it can treat TB with success rate of $99 \%$ and can avoid development of Multi-Drug Resistant Tuberculosis which poses a threat to global TB control [5]. In Nigeria, the DOTS program has been implemented in all states and local government areas in the country and over 3000 DOTS Centers have been operating across the country since 2006. However, in spite of all the DOTS Centers, Nigeria for over 10 years has remained on the fourth position of the countries with the highest burden of TB in the world [6].

WHO estimates that 210,000 new cases of all forms of TB occurred in Nigeria in 2010, and this is equivalent to 133 per 100,000 of the population. The age groups commonly affected by TB are the most productive age groups, with the 25 - 34 age group accounting for 33.6\% of the smear positive TB cases registered in 2010 [7]. One-third of the world's population is currently infected with TB, and the increasing association between HIV and TB poses a significant challenge [5] [7]. The HIV sero-prevalence rate among TB patients increased over the years from $2.2 \%$ in 1991 to $19.1 \%$ in 2001 and 25\% in 2010 [7]. HIV is the most powerful known risk factor for TB infection and progression to active disease. It increases the risk of latent TB reactivation 20-fold [8].

The term "adherence" refers to the extent to which patients follow a prescribed regimen [9]. About half of all patients with TB do not complete treatment and this contributes to prolonged infectiousness, drug resistance, relapse and death [10]. A study conducted in Ndola, Zambia among TB patients showed that $29.80 \%$ of the patients were non-adherent with their drugs. The major factors leading to non-adherence were feeling of recovery, ignorance, failure to procure drugs from the clinics, side effects of the drugs, poor nutrition, depression and forgetfulness [11]. Also, a study on the impact of medication side effects to treatment adherence showed that some of the observed side effects among patients were hepatitis, dyspepsia and arthralgia. These side effects were responsible for non-adherence treatment and failure to keep clinic appointments especially during the intensive phase. Similar characteristics were equally observed among both prison inmates and community-based patients in Northern Nigeria [9].

Drug resistance is caused by inconsistent or partial treatment due to patient's non-adherence, logistic factors, drug combinations, duration of treatment and poor attitude of health workers [5]. The difficulty experienced by patients to a particular treatment regimen, has raised awareness of adherence as a complex behavioral issue, influenced by many factors including gender and HIV/AIDS. WHO has attempted to classify factors that influence adherence to TB treatment, but the impact of gender and HIV status on adherence are less well documented in qualitative literature [10].

This study is aimed at assessing the adherence of TB patients to anti-TB medications as well as the factors influencing drug adherence in a tertiary health care institution in South-Eastern Nigeria. 


\section{Methodology}

A descriptive cross sectional study was conducted among TB patients receiving treatment at the DOTS Clinic in Nnamdi Azikiwe University Teaching Hospital, Nnewi, Anambra State, south east Nigeria.

The sample size was determined using the Fisher's formula [12]:

$N=\frac{z^{2} p q}{d^{2}}$

$N=$ minimum sample size

$z=$ standard normal deviate (1.96)

$p=$ prevalence of TB in a study conducted in Kano State, Nigeria $=14.7 \%$ [13]

$q=1-\mathrm{p}=1-0.147=0.853$

$d=$ degree of precision, set at $5 \%=0.05$

Substituting

$$
\begin{aligned}
N & =\frac{(1.96)^{2} \times 0.147 \times 0.853}{0.05 \times 0.05} \\
& =\frac{3.8416 \times 0.147 \times 0.853}{0.0025} \\
& =192
\end{aligned}
$$

The calculated sample size was 192. However, the total number of respondents enrolled into the study was increased to 217 to make provision for attrition.

Sample selection: The study was carried out in the month of February 2010. Thus, all consecutive patients who attended the DOTS clinic during the period of study were enrolled, if found eligible. A patient is eligible for enrollment, if the patient has been on anti-TB medications for at least four weeks. Also, only patients who gave an informed consent were enrolled into the study. The enrollment process continued daily until the required sample size of 217 was obtained.

Data collection: The study instrument was a semi-structured questionnaire which was designed to elicit information on socio demographic characteristics, adherence to drug medications and factors influencing drug adherence. This questionnaire was administered by two of the researchers of the study. No names were recorded on the questionnaire, to ensure confidentiality. Also respondents were assured that their responses will not be divulged to anyone under any circumstance.

Data analysis: Epi-Info Software Package was used in statistical analysis. Frequency distribution of all relevant variables was done. Relevant means and standard deviations were calculated. Tests of significance using Chi Square were conducted and the accepted level of significance is $5 \%$.

\section{Results}

Table 1 shows the socio-demographic characteristics of respondents. The mean age of the respondents is $36.1 \pm$ 13.3 years. More of the respondents were females (58.1\%), in comparison to $41.9 \%$ who were males. 91 (41.9\%) of the respondents acquired only primary school education, 87 (40.1\%) had secondary school education, while 24 (11.1\%) acquired tertiary education. The commonest occupation among the respondents was trading 97 (44.7\%).

Table 2 depicts adherence to anti-TB medications among respondents. It was shown that $74.7 \%$ of the patients never failed to take their drugs while $25.3 \%$ failed to take their anti-TB drugs as prescribed by a physician.

Table 3 shows the reasons given by respondents for failing to take their drugs. The major reasons given were no money for transport to collect new drugs 32.7\% and forgetfulness 32.7\%. Other reasons given by respondents were feeling of recovery, drugs finished, drugs make me feel sick and don't like taking drugs.

Table 4 depicts the effect of HIV on drug adherence. It was revealed that $28.1 \%$ of the respondents were receiving anti-retroviral drugs in addition to their anti-TB medications. Of this proportion, $61.0 \%$ said that they missed their anti-TB medications because of the HIV drugs. (It was noted that seven of the respondents voluntarily failed to give a response to the question on the co-administration of HIV drugs. This may be due to the discrimination and stigma associated with HIV/AIDS and they would thus, prefer not to disclose information related to their co-administration of HIV drugs.)

Table 5 shows the factors influencing adherence to anti-TB medications among respondents. Educational qualification and average monthly income significantly influenced drug adherence positively, while ill-health as 
Table 1. Socio-demographic characteristics of respondents $(n=217)$.

\begin{tabular}{|c|c|c|}
\hline Age & Frequency & Percentage \\
\hline$<20$ & 39 & 18.0 \\
\hline $20-30$ & 53 & 24.4 \\
\hline $31-40$ & 44 & 20.3 \\
\hline $41-50$ & 40 & 18.4 \\
\hline $51-60$ & 26 & 12.0 \\
\hline$>60$ & 15 & 6.9 \\
\hline Mean age & $36.1 \pm 13.3$ & \\
\hline \multicolumn{3}{|l|}{ Sex } \\
\hline Male & 91 & 41.9 \\
\hline Female & 126 & 58.1 \\
\hline \multicolumn{3}{|c|}{ Educational Qualification } \\
\hline Primary & 91 & 41.9 \\
\hline Secondary & 87 & 40.1 \\
\hline Tertiary & 24 & 11.1 \\
\hline None & 15 & 6.9 \\
\hline \multicolumn{3}{|l|}{ Occupation } \\
\hline Civil Servant & 39 & 18.0 \\
\hline Trader & 97 & 44.7 \\
\hline Artisan & 38 & 17.5 \\
\hline Student & 32 & 14.7 \\
\hline Others & 11 & 5.1 \\
\hline
\end{tabular}

Table 2. Socio-demographic characteristics of respondents $(n=217)$.

\begin{tabular}{lll}
\hline Adherence & Frequency & Percentage \\
\hline $\begin{array}{l}\text { Adhered to treatment } \\
\text { Failed to adhered to treatment }\end{array}$ & 162 & 74.7 \\
- $\quad$ Length of time drug was missed & 55 & 25.3 \\
o $<1$ month & 48 & 87.3 \\
o 1 - 2 months & 7 & 12.7 \\
Duration into treatment drug was missed & & \\
o $<2$ months & 27 & 49.1 \\
o 2 - 3 months & 18 & 32.7 \\
o 4 - 5 months & 6 & 10.9 \\
o Others & 4 & 7.3 \\
\hline
\end{tabular}


Table 3. Reasons for missing medication $(n=55)$.

\begin{tabular}{lll}
\hline Reasons & Frequency & Percentage \\
\hline Felt better & 7 & 12.7 \\
I forgot & 18 & 32.7 \\
Drugs finished & 3 & 5.5 \\
No money for transport to collect new drugs & 18 & 32.7 \\
Drugs make me feel sick & 3 & 5.5 \\
Don't like taking drugs & 3 & 5.5 \\
Others & 3 & 5.5 \\
\hline
\end{tabular}

Table 4. Effect of HIV on drug adherence $(n=210)$.

\begin{tabular}{lll}
\hline Co-administration of HIV drugs & Frequency & Percentage \\
\hline Receiving HIV drugs & 59 & 28.1 \\
- $\quad$ Cause to miss TB drugs because of HIV drugs & & 61.0 \\
o Missed TB drugs because of co-administration of HIV drugs & 36 & 39.0 \\
o Did not miss TB drugs because of co-administration of HIV drugs & 23 & \\
\hline
\end{tabular}

Table 5. Factors influencing TB drug adherence.

\begin{tabular}{|c|c|c|c|c|}
\hline Factor & Factor categories & $\%$ adherence & $\mathrm{X}^{2}$ & p-value \\
\hline Age & $\begin{array}{ll}\text { - } & <20 \\
\text { - } & 20-30 \\
\text { - } & 31-40 \\
\text { - } & 41-50 \\
\text { - } & 51-60 \\
\text { - } & >60\end{array}$ & $\begin{array}{l}76.9 \\
73.9 \\
65.9 \\
70.0 \\
88.5 \\
86.7\end{array}$ & 6.138 & 0.293 \\
\hline Sex & $\begin{array}{ll}\text { - } & \text { Male } \\
\text { - } & \text { Female }\end{array}$ & $\begin{array}{l}76.9 \\
73.0\end{array}$ & 0.426 & 0.532 \\
\hline Educational qualification & $\begin{array}{ll}\text { - } & \text { Primary } \\
\text { - } & \text { Secondary } \\
\text { - } & \text { Tertiary }\end{array}$ & $\begin{array}{l}74.4 \\
95.8 \\
86.7\end{array}$ & 9.627 & $0.022 *$ \\
\hline Occupation & $\begin{array}{ll}\text { - } & \text { Civil servant } \\
\text { - } & \text { Trader } \\
\text { - } & \text { Artisan } \\
\text { - } & \text { Student } \\
\text { - } & \text { Others }\end{array}$ & $\begin{array}{l}74.4 \\
74.2 \\
65.8 \\
90.6 \\
63.6\end{array}$ & 6.609 & 0.158 \\
\hline Distance to health facility (Km) & $\begin{array}{ll}\cdot & 10 \\
\cdot & 25 \\
- & 50 \\
- & >50\end{array}$ & $\begin{array}{l}67.9 \\
79.5 \\
79.5 \\
75.0\end{array}$ & 3.497 & 0.321 \\
\hline Average monthly income (\$) & $\begin{array}{ll}\bullet & <63 \\
\text { - } & 63-188 \\
\text { - } & 189-375 \\
\text { - } & >375\end{array}$ & $\begin{array}{l}61.8 \\
67.5 \\
64.7 \\
93.0\end{array}$ & 16.658 & $0.001^{*}$ \\
\hline Ill health as financial burden & $\begin{array}{l}\text { - } \quad \text { Burden } \\
\text { - } \quad \text { Not a burden }\end{array}$ & $\begin{array}{l}60.0 \\
88.0\end{array}$ & 21.382 & $0.000^{*}$ \\
\hline Receiving HIV drugs & $\begin{array}{ll}\text { - } & \text { Receiving } \\
\text { - } \quad \text { Not receiving }\end{array}$ & $\begin{array}{l}44.1 \\
85.4\end{array}$ & 37.547 & $0.000^{*}$ \\
\hline
\end{tabular}

*Statistically significant. 
financial burden and co-administration of HIV drugs significantly influence adherence negatively $(\mathrm{P}<0.05)$. However, age, sex, occupation and distance to health facility did not significantly influence drug adherence.

\section{Discussion}

The highest number of respondents in this study $24.4 \%$, was within the age range of 20 - 30 years. This is comparable with the findings of a prior study which revealed that the age group $20-29$ years had the highest number of TB respondents [14]. It was also noted that $18 \%$ of the respondents were less than 20 years of age with most of them within the pediatric age group. However, there were more females $58.1 \%$, than males $41.9 \%$. This contrasts with the findings of a prior study conducted in China which reported more male TB patients $69.5 \%$, than females 30.5\% [15]. Another study on adherence to anti-tuberculosis drugs done in Tanzania reported higher percentage of $57.2 \%$ for male patients, than $42.8 \%$ for female patients [16]. The higher percentage of female patients in this study may be because of the general attitude of men in this environment whereby they don't access healthcare until their health deteriorates to the extent that they can't carry out their daily activities effectively. Overall, $6.9 \%$ of the patients had no formal education. This is much lower than the findings of a study conducted in China where $27.1 \%$ of the patients had no formal education [15]. It is also lower in comparison with the findings of a study done in Uganda where $15 \%$ of the respondents had no formal education [17]. Most of the respondents in this present study were traders and this is generally similar with the findings of a prior study conducted in Ekiti State, Nigeria [18].

This study has demonstrated that $74.7 \%$ of the patients were adherent to their drugs. This adherence rate is lower than that seen in prior studies among TB patients in Tanzania and India which reported adherence rates of 95.7\% and 84\% respectively [16] [19]. A higher rate of 92.6\% was reported in Atlanta, Georgia USA [20]. In a review article on adherence rates in sub-Saharan Africa, a range of $70.4 \%$ - 88.4\% was reported [21]. However, a study conducted in Uganda reported an adherence rate of $75 \%$ while an adherence rate of $70 \%$ was demonstrated in Iran [17] [22] and these are comparable to the findings of this study. A lower rate of $65.1 \%$ was reported in Egypt [23]. It was also shown that $10.2 \%$ of the respondents in this study were not informed of the benefits of adherence and completion of drugs while $89.8 \%$ were. This shows the need to intensify the health education given to the patients so that they can fully understand the benefits of adherence and completion of their drugs.

It was observed that the commonest reasons given by the respondents for failure to take their medications were forgetfulness $32.7 \%$, and lack of money for transport to collect their drugs, $32.7 \%$. This could be because the patients come on a two weekly basis (during intensive phase) or one monthly (during continuation phase), hence and can easily forget about the drugs as compared to a situation whereby there is a Home-Based Directly Observed Therapy (HB-DOTS); in which the problem of forgetfulness will not arise. The HB-DOTS allows for the dispensing of medications to TB patients at their respective homes under the daily supervision of community volunteers who are selected by the health facilities and trained on TB treatment supervision. Also the complaint of transport money will not arise if it was a HB-DOTS setting. A prior study conducted in India demonstrated that concern about transportation cost was significantly associated with non-adherence to TB treatment [19]. Similar findings were also reported in Madagascar and Malaysia [24] [25].

It was also revealed that $28.1 \%$ of the respondents in this study were receiving drugs for HIV as well. A prior study carried out in Kenya demonstrated that $34 \%$ of the HIV infected TB patients were receiving anti-retroviral drugs as well [26]. This study showed that educational qualification, average monthly income, ill-health being a financial burden and receiving HIV drugs were observed as the factors which influenced drug adherence $(\mathrm{P}<$ 0.05). These are understandable because a more educated patient is more likely to understand the reasons for adherence and is more likely to adhere than an uneducated patient. It was also revealed that the highest number of the respondents 34.2\% have an average monthly income of $\$ 189$ - \$375. Also almost half of the respondents, $49 \%$ spend $20 \%-49 \%$ of their monthly income on health services. Thus, these patients will obviously find it difficult to keep appointments to collect their drugs due to financial problems. Being HIV positive can affect adherence to anti-TB drugs in several ways. One is that the drug burden is increased as the patient will be taking both anti-TB drugs and antiretroviral drugs. Also the patient will have more hospital visits which will affect him financially both in terms of direct cost and opportunity cost when he has to forgo his daily money earning activities to go to the hospital. It has been reported that WHO has attempted to classify factors that influence adherence to TB treatment but the impact of gender and HIV status on adherence are less well documented in qualit- 
ative literature [10]. However, this study has demonstrated that gender did not have a significant influence on adherence to anti-TB medications while HIV status significantly influenced adherence to anti-TB medications negatively.

Majority of the respondents in this study, $87.3 \%$ had the desire to complete treatment, while $12.7 \%$ did not have the desire to complete treatment. Having no desire to complete treatment could be attributed to the reasons given by respondents for non-adherence to medications which include no money for transport to collect new drugs, forgetfulness, feeling of recovery and the drugs make me feel sick among others.

\section{Conclusion}

Adherence to anti-TB medications is good. It was also shown that some of the respondents in this study were not informed of the benefits of adherence and completion of drugs. However, educational qualification, average monthly income, ill-health being a financial burden and receiving HIV drugs influenced drug adherence. Some of the respondents in this present study did not have the desire to complete their treatment. Having no desire to complete treatment could be attributed to the reasons given by respondents for non-adherence to medications which include no money for transport to collect new drugs, forgetfulness, feeling of recovery and the drugs make me feel sick among others.

\section{Recommendations}

There is a need for the government to introduce HB-DOTS, so that the financial burden on patients will be eliminated. This will also eliminate the effect of forgetfulness. At the onset of TB treatment, patients should be introduced to both HB-DOTS and Facility Based Directly Observed Therapy (FB-DOTS) and should be given the privilege to choose which of these methods they prefer.

Health education on the benefits of adherence as well as the dangers of non-adherence should be intensified. This will enable the patients to fully understand the adverse effects of non-adherence on their health.

Periodic health education should be conducted after the patients have commenced anti-TB medications. This will ensure sustainability of information obtained and will ultimately improve adherence.

It is also required that TB and HIV services should be fully integrated so that patients with TB/HIV co-infection do not have to visit two different clinics.

\section{Conflict of Interest}

None declared.

\section{Funding}

The article was funded by the researchers themselves.

\section{References}

[1] Giles, H.N. and Lucas, A.O. (2003) A Short Textbook of Public Medicine for the Tropics and Sub-Tropics. 4th Edition, Arnold, A Member of the Hodder Headline Group, London, 159-163.

[2] Kumar, V., Abbas, A.K. and Fausto, N. (2004) Robbins and Cotrane Pathological Basis of Disease.7th Edition, Elsevier, A Division of Reed Elsevier India Private Limited, New Delhi, 381.

[3] Nicholas, A.B., Nicki, R.C. and Brian, R.W. (2006) Davidson's Principles and Practice of Medicine. 20th Edition, Elsevier Limited, Edinburgh, 675-696.

[4] False, A.O. and Akinkugbe, O.O. (2002) A Compendium of Clinical Medicine. 2nd Edition, Spectrum Books Limited, Ibadan, 163-165.

[5] The Guardian Newspaper (2009) The Race against Tuberculosis Burden.

[6] Udoh, F. (2012) Nigeria: Burden of Tuberculous Disease in Nigeria. http://allafrica.com/stories/201207020161.html

[7] United States Embassy in Nigeria (2012) Nigeria Tuberculosis Fact Sheet 2012. http://nigeria.usembassy.gov./

[8] Pawlowski, A., Jansson, M., Skold, M., Rottenberg, M.E. and Kallenius, G. (2012) Tuberculosis and HIV Co-Infection. 
PLOS Pathogens, 8, 1002464. http://dx.doi.org/10.1371/journal.ppat.1002464

[9] Awofeso, N. (2008) A Study on Impact of Medication Side Effects on Treatment Adherence to Tuberculosis in Kyrgyzstan Prison. WHO Bulletin, 86, 161.

[10] Munro, S.A., Lewin, S.A., Smith, H.J., Engel, M.E., Fretheim, A. and Volmink, J. (2007) Patient Adherence to Tuberculosis Treatment : A Systematic Review of Qualitative Research. PLOS Medicine, 4, e238. http://dx.doi.org/10.1371/journal.pmed.0040238

[11] Kaona, F.A.D., Tuba, M., Siziya, S. and Sikaona, L. (2004) An Assessment of Factors Contributing to Treatment Adherence and Knowledge of Tuberculosis Transmission among Patients on Tuberculosis Treatment. BMC Public Health, 4, 68. http://dx.doi.org/10.1186/1471-2458-4-68

[12] Araoye, M.O. (2003) Research Methodology with Statistics for Health and Social Sciences. Nathadex Publishers, Ilorin, 120.

[13] Imam, T.S. and Oyeyi, T.I. (2008) A Retrospective Study of Pulmonary Tuberculosis (PTB) Prevalence amongst Patients Attending Infectious Diseases Hospital (IDH) in Kano, Nigeria. Bayero Journal of Pure and Applied Sciences, 1, 10-15.

[14] Nwene, E. (2014) An Evaluation of Treatment Outcome in Tuberculosis Directly Observed Treatment Short Course (DOTS) Facilities in Anambra State (2004-2008). Unpublished Master's Thesis, Nnamdi Azikiwe University, Awka. http://naulibrary.org/dglibrary/admin/book_directory/Thesis/10363.pdf

[15] Yao, S., Huang, W., Van den Hof, S., Yang, S., Wang, X., Chen, W., et al. (2011) Treatment Adherence among Sputum Smear-Positive Pulmonary Tuberculosis Patients in Mountainous Areas in China. BMC Health Services Research, 11, 341. http://dx.doi.org/10.1186/1472-6963-11-341

[16] Mkopi, A., Range, N., Lwila, F., Egwaga, S., Schulze, A., Geubbels, E., et al. (2012) Adherence to Tuberculosis Therapy among Patients Receiving Home-Based Directly Observed Treatment: Evidence from the United Republic of Tanzania. Plos ONE, 7, e51828. http://dx.doi.org/10.1371/journal.pone.0051828

[17] Amuha, M.G., Kutyabami, P., Kitutu, F.E., Odoi-Adome, R. and Kalyango, J.N. (2009) Non-Adherence to Anti Tuberculosis Drugs among TB/HIV Co-Infected Patients in Mbarara Hospital Uganda: Prevalence and Associated Factors. African Health Sciences, 9, 8-15.

[18] Oluwadare, C. and Ibirinde, B. (2010) Health Seeking Behavior of Tuberculosis Patients in Ekiti State, Nigeria. EthnoMed, 4, 191-197.

[19] Bagchi, S., Ambe, G. and Sathiakumar, N. (2010) Determinants of Poor Adherence to Anti-Tuberculosis Treatment in Mumbai India. International Journal of Preventive Medicine, 1, 223-232.

[20] McDonnell, M., Turner, J. and Weaver, M.T. (2001) Antecedents of Adherence to Anti Tuberculosis Therapy. Public Health Nursing, 18, 392-400. http://dx.doi.org/10.1046/j.1525-1446.2001.00392.x

[21] Castlenuovo, B. (2010) A Review of Compliance to Anti Tuberculosis Treatment and Risk Factors for Defaulting Treatment in Sub-Saharan Africa. African Health Sciences, 10, 320-324.

[22] Khalili, H., Dashti-khavidaki, S., Sajadi, S. and Hajiabolbaghi, M. (2008) Assessment of Adherence to Tuberculosis Drug Regimen. DARU, 16, 47-50.

[23] Gad, A., Mandil, A.M., Sherif, A.A., Gad, Z.M. and Sallam, S. (1997) Compliance with Anti-Tuberculosis Drugs among Tuberculosis Patients in Alexandria, Egypt. La Revue de Santé Méditerrannée orientale, 3, 244-250.

[24] Comolet, T.M., Rakotomalala, R. and Rajaonarioa, H. (1998) Factors Determining Compliance with Tuberculosis Treatment in an Urban Environment, Tamatave, Madagascar. The International Journal of Tuberculosis and Lung Disease, 2, 891-897.

[25] Naing, N.N., D’Este, C., Isa, A.R., Salleh, R., Bakar, N. and Mahmod, M.R. (2001) Factors Contributing to Poor Compliance with Anti-Tuberculosis Treatment among Tuberculosis Patients. The Southeast Asian Journal of Tropical Medicine and Public Health, 32, 369-382.

[26] Center for Disease Control (2010) HIV Testing and Treatment among Tuberculosis Patients in Kenya, $2006-2009$. Morbidity and Mortality Weekly Report (MMWR), 59, 1514-1517. 